\title{
Pre-1938 Indicator
}

National Cancer Institute

\section{Source}

National Cancer Institute. Pre-1938 Indicator. NCI Thesaurus. Code C93630.

Specifies whether the entity qualifies under the 1938 Grandfather Clause, contained in section 20l(p)(I) of the U.S. Federal Food, Drug and Cosmetic Act. 